\title{
BMJ Open Corporal punishment bans and physical fighting in adolescents: an ecological study of 88 countries
}

\author{
Frank J Elgar, ${ }^{1}$ Peter D Donnelly, ${ }^{2}$ Valerie Michaelson, ${ }^{3}$ Geneviève Gariépy, ${ }^{1}$ \\ Kira E Riehm, ${ }^{4}$ Sophie D Walsh, ${ }^{5}$ William Pickett ${ }^{2}$
}

To cite: Elgar FJ, Donnelly PD, Michaelson V, et al. Corporal punishment bans and physical fighting in adolescents: an ecological study of 88 countries. BMJ Open 2018;8:e21616. doi:10.1136/ bmjopen-2018-021616

- Prepublication history and additional material for this paper are available online. To view these files, please visit the journal online (http://dx.doi. org/10.1136/bmjopen-2018021616).

Received 9 January 2018 Revised 25 June 2018 Accepted 1 August 2018

Check for updates

(c) Author(s) (or their employer(s)) 2018. Re-use permitted under CC BY-NC. No commercial re-use. See rights and permissions. Published by BMJ.

${ }^{1}$ Institute for Health and Social Policy, McGill University, Montreal, Quebec, Canada ${ }^{2}$ Department of Public Health Sciences, Queen's University, Kingston, Ontario, Canada ${ }^{3}$ School of Religion, Queen's University, Kingston, Ontario, Canada

${ }^{4}$ Department of Mental Health, Bloomberg School of Public Health, Johns Hopkins University, Baltimore, Maryland, USA

${ }^{5}$ Department of Criminology, Bar-llan University, Ramat-Gan, Israel

Correspondence to

Dr Frank J Elgar;

frank.elgar@mcgill.ca

\section{ABSTRACT}

Objective To examine the association between corporal punishment bans and youth violence at an international level.

Design Ecological study of low-income to high-income 88 countries.

Setting School-based health surveys of students. Participants 403604 adolescents.

Interventions National corporal punishment bans. Primary outcome measure Age-standardised prevalence of frequent physical fighting (ie, 4+ episodes in the previous year) for male and female adolescents in each country.

Results Frequent fighting was more common in males $(9.9 \%, 95 \% \mathrm{Cl} 9.1 \%$ to $10.7 \%)$ than females $(2.8 \%, 95 \% \mathrm{Cl}$ $2.5 \%$ to $3.1 \%$ ) and varied widely between countries, from $0.9 \%$ (95\% Cl $0.8 \%$ to $0.9 \%)$ in Costa Rican females to $34.8 \%$ (95\% Cl 34.7 to 35.0 ) in Samoan males. Compared with 20 countries with no ban, the group of 30 countries with full bans (in schools and in the home) experienced $69 \%$ the rate of fighting in males and $42 \%$ in females. Thirty-eight countries with partial bans (in schools but not in the home) experienced less fighting in females only ( $56 \%$ the rate found in countries without bans).

Conclusions Country prohibition of corporal punishment is associated with less youth violence. Whether bans precipitated changes in child discipline or reflected a social milieu that inhibits youth violence remains unclear due to the study design and data limitations. However, these results support the hypothesis that societies that prohibit the use of corporal punishment are less violent for youth to grow up in than societies that have not.

\section{INTRODUCTION}

Corporal punishment is an adult's use of physical force to correct or control a child's inappropriate behaviour. ${ }^{12}$ The punishment is intended to cause pain but does not physically injure the child. Its use remains legally and socially permitted in many countries. Unicef reported that an estimated $17 \%$ of adolescents worldwide have experienced corporal punishment either at school or in the home during the past month. ${ }^{3}$ Proponents of corporal punishment argue that physical discipline is benign or even beneficial to the long-term

\section{Strengths and limitations of this study}

The Health Behaviour in School-aged Children study and Global School-based Health Survey are wellestablished international surveys of adolescents.

- The study includes a diverse sample of countries and is one of the largest cross-national analyses of youth violence.

- Causal associations could not be inferred due to data gaps and the ecological study design.

- It remains unclear whether bans precipitate change in child discipline or reflect a social milieu that inhibits youth violence.

health of the child. ${ }^{4}$ However, a persuasive body of evidence challenges this view. Several independent investigations have found that children's exposure to corporal punishment relates to aggressive behaviours, ${ }^{5-10}$ mental health problems, ${ }^{11-15}$ academic problems and related cognitive deficits. ${ }^{16-18}$ Such outcomes have lifelong consequences for adult health and well-being. A meta-analysis of 75 studies found that childhood exposure to spanking, the most common form of corporal punishment, predicted 13 of 17 negative outcomes including aggression, antisocial behaviour, mental health problems, low self-esteem and physical abuse, and to antisocial behaviour and poor mental health in adulthood. ${ }^{15} \mathrm{~A}$ study of partner violence in six Asian and Pacific countries found that men's experience of harsh physical parenting during their childhood related to violence against women in adulthood. ${ }^{19}$

Various psychological theories have been used to describe the possible underlying pathways in the association between corporal punishment and youth violence. According to social learning and social interaction theories, children and adolescents learn from corporal punishment that physical violence is an effective and permissible way of settling conflicts and influencing the behaviour of 
others. ${ }^{20}{ }^{21}$ Script theory suggests that repeated corporal punishment constructs a stable set of beliefs (ie, cognitive script) in the child's mind that becomes increasingly salient and accessible depending on the frequency of corporal punishment. ${ }^{22}$ Similarly, the general aggression model describes how repeated exposures to corporal punishment reinforce aggressive thoughts, emotions and actions towards others. ${ }^{23}$ These theories help to explain the intergenerational cycle of physical violence from early childhood experiences to later violent behaviour.

Moreover, a child's rights perspective recognises that corporal punishment violates children's rights to personal integrity, human dignity and protection from all forms of violence as guaranteed under the United Nations Convention on the Rights of the Child. ${ }^{24}$ The Convention states that the elimination of corporal punishment is 'not only an obligation of States parties' but also a 'key strategy for reducing and preventing all forms of violence'. ${ }^{24}$ The prohibition of corporal punishment might help protect children from harm and support their social development. ${ }^{1825}$ However, while legal prohibition has led to decreased use and decreased public support for corporal punishment in some countries, ${ }^{26}$ the association between bans on corporal punishment and youth physical violence has not been examined at an international level. The reason for this may be a lack of comparable data on youth violence from a large sample of legal jurisdictions. Investigating the association at the country level requires a large and diverse sample of countries so that other social and structural determinants of violence can be controlled with adequate statistical power.

We had an opportunity to examine this association in a large and diverse group of countries, territories and protectorate states (hereafter described collectively as 'countries') that carried out similar school-based surveys of adolescents. By harmonising their data in country-level prevalence estimates of frequent physical fighting, our goal was to investigate the association between the legal prohibition of corporal punishment and frequent fighting among adolescents. We hypothesised that national corporal punishment bans were associated with lower rates of fighting among adolescents.

\section{METHODS}

Data sources

Survey data

Two well-established school-based surveys have measured physical fighting in adolescents: the WHO Health Behaviour in School-aged Children (HBSC) study and the Global School-based Health Survey (GSHS). The HBSC surveys children aged 11, 13 and 15 years in Canada, the USA and most European countries every 4years following a common protocol. ${ }^{27}$ Its self-completion questionnaire measures physical fighting with the item: "In the past 12 months, how many times were you in a physical fight $(0,1,2,3,4$ or more)?" We used data from 32 countries that participated in the most recent HBSC survey in 2014 (Albania, Armenia, Austria, Belgium, Bulgaria, Canada, Croatia, Czech Republic, Estonia, Finland, Germany, Great Britain, Iceland, Israel, Italy, Latvia, Lithuania, Macedonia, Moldova, The Netherlands, Norway, Poland, Portugal, Romania, Russian Federation, Slovakia, Slovenia, Spain, Sweden and Switzerland). We supplemented these records with data from Turkey and the USA that were collected in the 2010 HBSC survey because they were missing from the 2014 cycle. Data collected in regional surveys in French and Flemish regions of Belgium were combined with equal weight, as were data from England, Scotland and Wales in the UK.

The GSHS provides data on physical fighting among those aged 13-17 years in 55 low-income and middle-income countries. Its questionnaire includes a similar survey item on physical fighting: "In the past 12 months, how many times were you in a physical fight $(0,1,2-3$, $4-5,6-7,8-9,10-11,12$ or more)?" We used data from 55 surveys that were carried out between 2003 and 2016 in Algeria, Belize, Benin, Bolivia, Botswana, Brunei,

\begin{tabular}{|c|c|c|c|c|c|}
\hline Variable & n (\%) & Range & Mean & SD & $95 \% \mathrm{Cl}$ \\
\hline Frequent fighting, 1-year prevalence, males (\%) & & 1.82 to 34.78 & 9.92 & 6.63 & 9.09 to 10.74 \\
\hline Income per capita (US\$, thousands) & & 0.36 to 105.81 & 17.16 & 22.14 & 12.47 to 21.86 \\
\hline Homicides (per 1 million) & & 0.00 to 8.55 & 0.80 & 1.39 & 0.51 to 1.10 \\
\hline in schools and in the home & $30(34.09)$ & & & & 24.81 to 44.78 \\
\hline in schools, not in the home & $38(43.18)$ & & & & 33.08 to 53.89 \\
\hline neither schools nor home & $20(22.73)$ & & & & 15.03 to 32.84 \\
\hline Weapons ban at school & $71(80.68)$ & & & & 70.88 to 87.75 \\
\hline Home visits for child maltreatment & $73(82.95)$ & & & & 73.41 to 89.56 \\
\hline
\end{tabular}

Frequent fighting is weighted by the inverse variance of the prevalence. 
Cambodia, China, Colombia, Cook Islands, Costa Rica, Dominica, Ecuador, Egypt, El Salvador, Fiji, Ghana, Guyana, Honduras, Indonesia, Iraq, Jamaica, Jordan, Kenya, Kiribati, Kuwait, Malawi, Malaysia, Maldives, Mauritania, Mongolia, Morocco, Myanmar, Oman, Peru, The Philippines, Qatar, Samoa, Solomon Islands, Swaziland, Tajikistan, Tanzania, Thailand, Trinidad and Tobago, Tunisia, Tuvalu, Uganda, United Arab Emirates, Vanuatu, Vietnam, West Bank and Gaza, Yemen, Zambia and Zimbabwe.

Comparable data from New Zealand were supplied by the Youth2012 survey, which used the following item on physical fighting in 8500 children aged 13-18 years in 2012: "In the last 12 months, how many times were you in a serious physical fight (none, 1-2, 3, 4, 5 or more)?"28 Finally, data from South Africa were supplied by the 2011 Youth Risk Behaviour Survey (YRBS) in which 10707 participants aged 12-25 years were asked "During the past 6 months, how often were you in a physical fight (eg, punching, hitting; never, rarely (one time), sometimes (two or three times), often (four or five times) or very often (six or more times))?"29 Together, our study used 403604 individual records from 8545 schools in 88 national surveys. Each national survey was weighted to be representative of the country's population of adolescents. At the time of our analysis, this group of 88 countries were home to approximately $45.7 \%$ of the world's population of adolescents.

Student participation in these surveys was voluntary and active or passive consent was sought from school administrators, parents and children as per national human participant requirements. Youth in private and special needs schools and street and incarcerated youth were excluded. All national surveys used two-stage sampling of schools that represented the geographic and economic diversity in each country, and then classes within schools that provided their target age group. Teachers or trained interviewers administered the survey questionnaire in classroom settings.

\section{Country data}

The Global Initiative to End All Corporal Punishment of Children provided data on national prohibition of corporal punishment in the home, alternative care settings, day cares, schools and penal institutions and as a sentence for a crime. ${ }^{30}$ We categorised the 88 countries in our sample as having either full prohibition (in schools and in the home, which was equivalent to prohibition in all settings; $n=30$ ), partial prohibition (in schools but not in the home; $\mathrm{n}=38$ ) or no prohibition (neither in schools nor in the home; $n=20)$.

A 2014 WHO report on violence supplied contemporary data on relevant country characteristics and antiviolence policies. We used these variables to try to control for other determinants of youth violence and a varying cultural propensity for violence: homicides per 100000 population, weapons ban in schools, home visitation programmes to prevent child maltreatment, parent

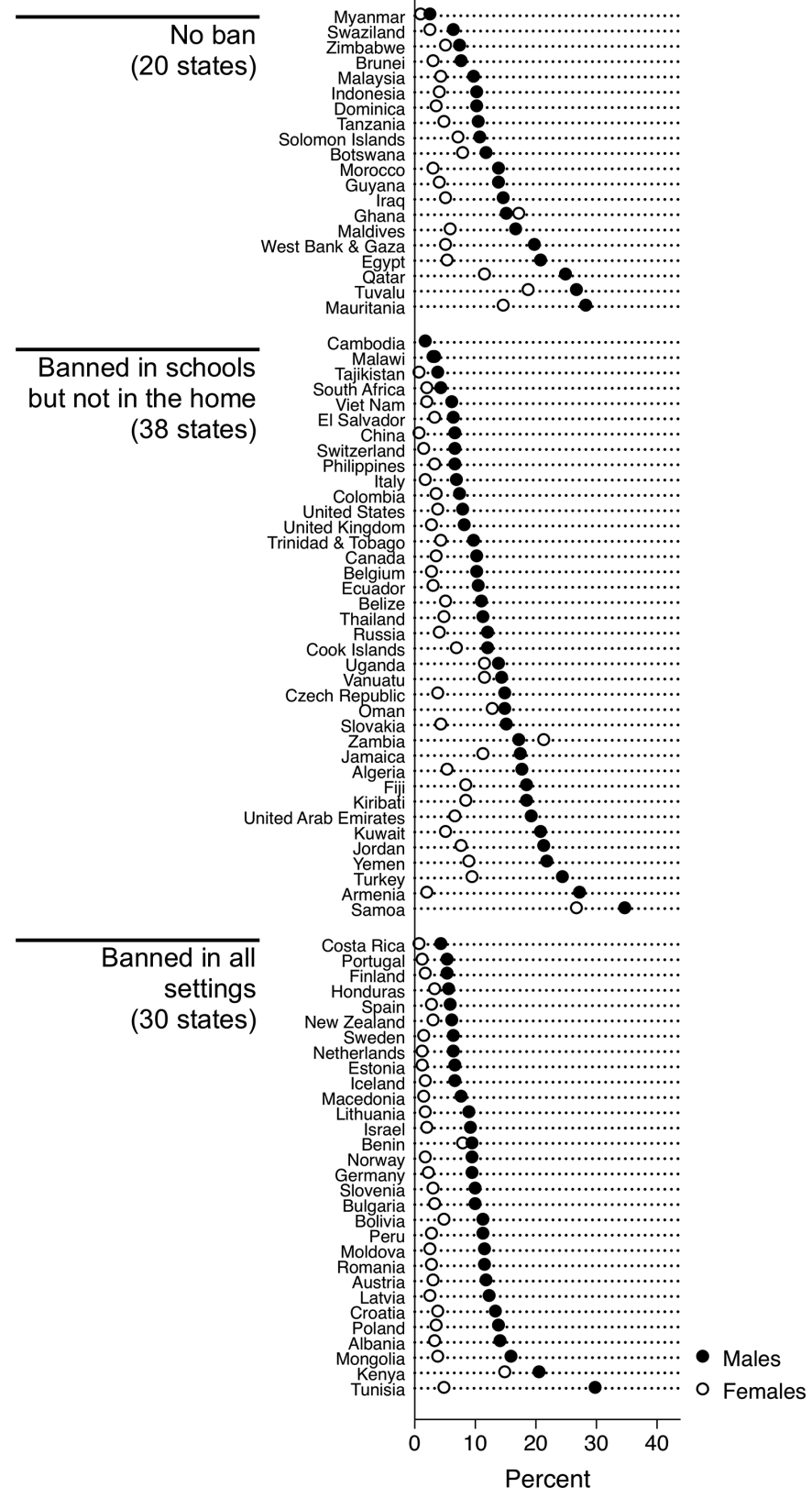

Figure 1 Prevalence of frequent physical fighting in male and female adolescents in 88 countries and territories (sorted by prevalence in males). Details about country probation laws are available at http://www.endcorporalpunishment.org.

education programmes that teach positive discipline techniques and child development and ban on capital punishment. ${ }^{31}$ We also included World Bank estimates of gross national income per capita to statistically control differences in country wealth. ${ }^{32}{ }^{33}$ Income data were adjusted for purchasing parity and reported in standardised current international dollars. The data are summarised in online supplementary table 1 .

\section{Data analysis}

The analysis was carried out in two phases. We first calculated a weighted, age-standardised prevalence of frequent physical fighting for males and females in each country. Second, these prevalence estimates were linked to other 
Table 2 Rate ratio of frequent physical fighting in males aged 13 years

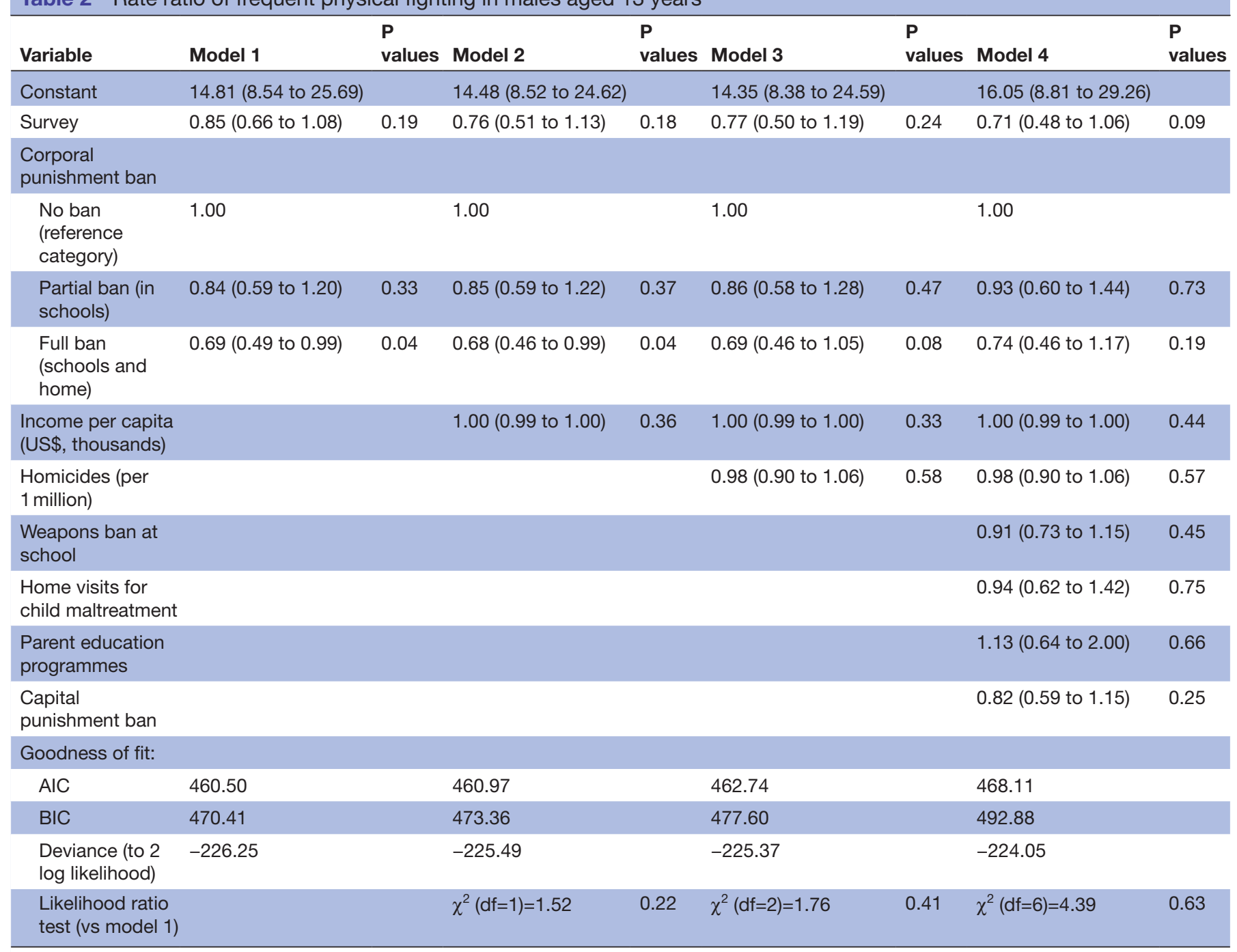

95\% Cl shown in parentheses.

AIC, Akaike Information Criterion; BIC, Bayesian Information Criterion.

country characteristics in an ecological regression analysis of country differences.

First, we analysed the individual records on all 403604 cases combined and estimated the prevalence of frequent physical fighting (4+ episodes in the past year) separately in males and females in each country. Age standardisation was required given the slight age differences between the surveys. The cut-point criterion of $4+$ episodes of physical fighting was consistent with previous studies of chronic violent behaviour. ${ }^{33}$ The prevalence estimations were carried out using STATA V.14.2 (StataCorp, College Station, Texas, USA) by fitting a logistic regression model to the data and then estimating the predicted prevalence at age 13 using Stata's margins command. The analyses used sampling weights and SEs were adjusted for schoollevel clustering. The intraclass correlation in frequent fighting at the school level was 0.12 (95\% CI 0.11 to 0.12 ), which is indicative of a small clustering effect of school.

We then linked the national prevalence of frequent fighting and SEs of the prevalence to other country-level characteristics (income per capita, homicides, weapons bans, home visits and capital punishment bans; see online supplementary table 1). Income inequality was not included due to its collinearity with homicides $(r=0.52$, $\mathrm{p}<0.01$ ). Homicides per 100000 persons were scaled to homicides per 1 million to better show its associations in regression analyses. The significance of associations between full or partial bans and frequent physical fighting was tested using Poisson regression and reported as incidence rate ratios (IRR). Analytic weights were applied using DerSimonian and Laird's inverse-variance method $\left(1 / \mathrm{SE}^{2}\right)$, which effectively shifts weight towards more precise prevalence estimates. ${ }^{34} \mathrm{~A}$ dummy variable was applied to the models to control fixed effects of unmeasured differences in survey methods between the surveys (coded 0 (HBSC, Youth2012) or 1 (GSHS, South African YRBS) ). There were no missing data at the country level.

Goodness of fit of the models to the data was evaluated using the Akaike Information Criterion (AIC) - a measure of model deviance (d) adjusted for the number 
Table 3 Rate ratio of frequent physical fighting in females aged 13 years

\begin{tabular}{|c|c|c|c|c|c|c|c|c|}
\hline Variable & Model 1 & $\begin{array}{l}P \\
\text { values }\end{array}$ & Model 2 & $\begin{array}{l}P \\
\text { values }\end{array}$ & Model 3 & $\begin{array}{l}P \\
\text { values }\end{array}$ & Model 4 & $\begin{array}{l}\mathbf{P} \\
\text { values }\end{array}$ \\
\hline Constant & 5.35 (3.18 to 8.99$)$ & & 5.94 (3.32 to 10.62$)$ & & 6.12 (3.43 to 10.91$)$ & & $6.10(2.41$ to 15.42$)$ & \\
\hline Survey & 0.87 (0.57 to 1.33$)$ & 0.03 & $0.80(0.51$ to 1.28$)$ & 0.36 & $0.73(0.44$ to 1.21$)$ & 0.22 & $0.71(0.43$ to 1.20$)$ & 0.20 \\
\hline \multicolumn{9}{|l|}{ Corporal punishment ban } \\
\hline No ban (reference category) & 1.00 & & 1.00 & & 1.00 & & 1.00 & \\
\hline Partial ban (in schools) & $0.56(0.33$ to 0.95$)$ & 0.03 & 0.57 (0.33 to 0.96$)$ & 0.03 & $0.52(0.30$ to 0.90$)$ & 0.02 & 0.51 (0.28 to 0.92$)$ & 0.03 \\
\hline Full ban (schools and home) & $0.42(0.25$ to 0.70$)$ & $<0.01$ & 0.41 (0.24 to 0.69$)$ & $<0.01$ & $0.37(0.21$ to 0.65$)$ & $<0.01$ & 0.35 (0.19 to 0.67$)$ & $<0.01$ \\
\hline Income per capita (US\$, thousands) & & & 1.00 (0.99 to 1.00$)$ & 0.38 & $1.00(0.99$ to 1.00$)$ & 0.57 & 1.00 (0.99 to 1.00$)$ & 0.35 \\
\hline Homicides (per 1 million) & & & & & 1.14 (1.01 to 1.28$)$ & 0.03 & $1.13(1.01$ to 1.26$)$ & 0.03 \\
\hline Weapons ban at school & & & & & & & 1.05 (0.79 to 1.40$)$ & 0.73 \\
\hline Home visits for child maltreatment & & & & & & & 0.83 (0.52 to 1.32$)$ & 0.43 \\
\hline Parent education programmes & & & & & & & $1.18(0.57$ to 2.46$)$ & 0.65 \\
\hline Capital punishment ban & & & & & & & $1.07(0.74$ to 1.55$)$ & 0.73 \\
\hline \multicolumn{9}{|l|}{ Goodness of fit: } \\
\hline $\mathrm{AIC}$ & 300.81 & & 302.49 & & 302.42 & & 309.60 & \\
\hline $\mathrm{BIC}$ & 310.72 & & 314.87 & & 317.28 & & 334.37 & \\
\hline Deviance (-2 log likelihood) & -146.41 & & -146.24 & & -145.21 & & -144.80 & \\
\hline Likelihood ratio test (vs model 1 ) & & & $\chi^{2}(d f=1)=0.33$ & & $\chi^{2}(\mathrm{df}=2)=2.40$ & & $\chi^{2}(\mathrm{df}=6)=3.22$ & 0.78 \\
\hline
\end{tabular}

$95 \% \mathrm{Cl}$ shown in parentheses.

AIC, Akaike Information Criterion; BIC, Bayesian Information Criterion.

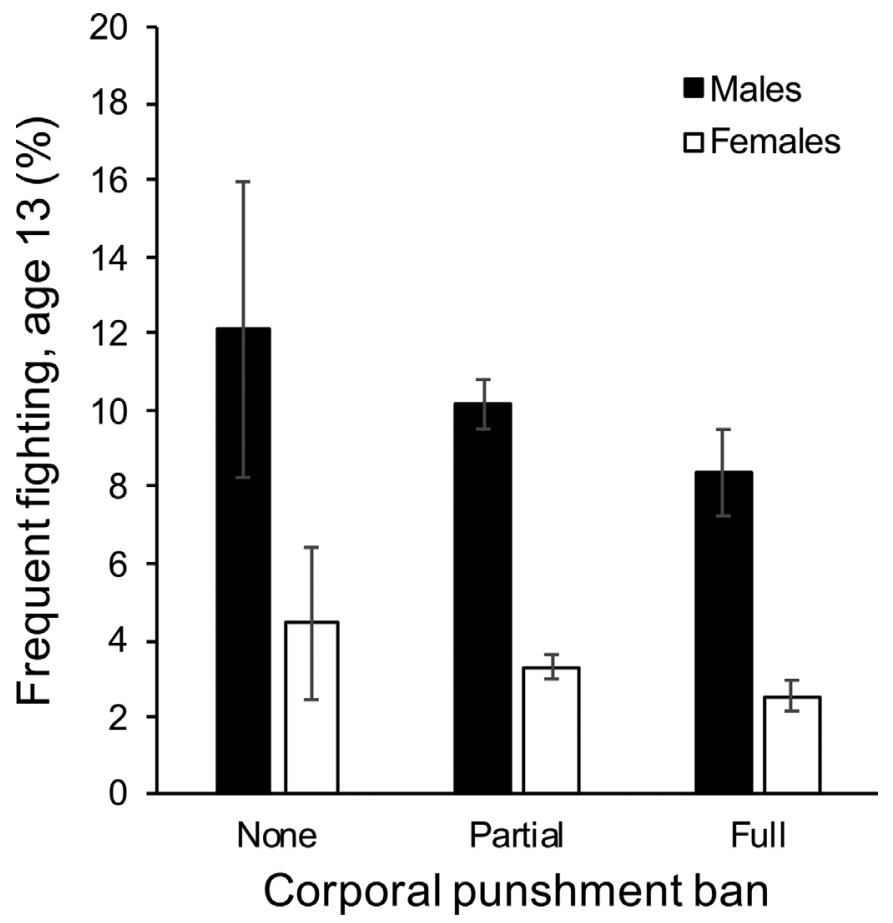

Figure 2 Predicted prevalence of frequent physical fighting at age 13 in countries with no prohibition $(n=20)$, partial prohibition (in schools but not in the home; $n=38$ ) and full prohibition (banned in all settings; $n=30$ ). Shown are means and $95 \% \mathrm{Cl}$ adjusted for survey differences and school clustering.

of parameters $(q)$ in the model $(A I C=d+2 q)$, and the more conservative Bayesian Information Criterion (BIC), which also corrects for differences in the number of observations $(\mathrm{n})$ in the model $(\mathrm{BIC}=\mathrm{d}+\log (\mathrm{n}) \times \mathrm{q}) \cdot{ }^{35}$ Smaller
AIC and BIC values indicate better model fit. We also used the log-likelihood ratio test to determine whether adding variables to the model significantly improved its fit to the data.

\section{Patient involvement}

No patients were involved in developing the research question or the outcome measures, nor were they involved in planning the design, recruitment to and conduct of the study. No patients were asked to advise on the interpretation or writing up of results. There are no plans to disseminate the results of the research to study participants.

\section{RESULTS}

Table 1 provides descriptive statistics on the main variables. Frequent physical fighting was more than three times as common in males $(9.92 \%, 95 \%$ CI $9.09 \%$ to $10.74 \%)$ than in females $(2.81 \%, 95 \%$ CI $2.48 \%$ to $3.13 \%)$ and varied widely between countries, from $0.86 \%(95 \%$ CI 0.81 to 0.91$)$ in Costa Rican females to $34.78 \%(95 \%$ CI 34.69 to 34.97 ) in Samoan males. Per capita incomes ranged from US\$360 (Malawi) to US\$105810 (Norway). Homicides ranged from 0 (Iceland) to 8.55 (Honduras) per 1 million. Thirty $(34.09 \%)$ countries in our sample had prohibited the use of corporal punishment in all settings, $38(43.18 \%)$ prohibited corporal punishment in schools but not in the home and 20 (22.73\%) had not prohibited corporal punishment in schools or in the home. Most countries had banned weapons in schools $(n=71,80.68 \%)$ and used home visits $(n=73,82.95 \%)$ and parent education programmes $(n=81,92.05 \%)$ to prevent child maltreatment. Capital punishment was banned in 
$41(46.59 \%)$ of the countries. The dot plot in figure 1 shows the diversity of low-income, middle-income and high-income countries in the study and heterogeneity in the prevalence of frequent physical fighting. The figure also shows a consistent gender gap in fighting, with a higher prevalence in males than in females in all but two countries (Ghana and Zambia).

Table 2 summarises our regression analysis of frequent fighting in males. We tested four nested models that were progressively more complex. Model 1 tested the crude association between corporal punishment bans and frequent physical fighting whereby the only control was a fixed effect of the school survey. Full bans on corporal punishment (ie, school and home) corresponded with a rate ratio of 0.69 (95\% CI 0.49 to 0.99 ), meaning that countries with full bans had $69 \%$ the rate of frequent fighting found in countries without a ban. Partial bans (ie, schools only) did not significantly reduce the rate of fighting in males. In model 2, the association with full bans held up to an added control for country wealth; however, in models 3 and 4 the association was no longer significant after taking other correlates into account (despite no significant associations found with homicides, weapons bans, home visits or parent education programmes and capital punishment). The non-significant changes in goodness of fit, as tested in a log-likelihood ratio test, indicated that these larger models were no more accurate than model 1 .

The same analysis applied to frequent physical fighting in females showed a closer association with corporal punishment bans. As shown in table 3, countries with either a full or partial ban on corporal punishment showed significantly lower rates of frequent fighting than in countries without such bans. This time, the associations held up to additional statistical controls in models 2, 3 and 4 . The fully adjusted model 4 also indicated that homicides related to higher rates of fighting in females (IRR=1.13 (95\% CI 1.01 to 1.26) ), although the model's goodness of fit was not significantly improved over model 1 .

Using model 1 as the most parsimonious representation of the data, we then calculated the predicted prevalence of frequent physical fighting in males and females in each country and plotted these values in figure 2 . This chart-like the regression models-shows less frequent physical fighting in those countries that prohibited the use of corporal punishment in the home. Specifically, countries that enacted a total ban on corporal punishment in schools and in the home, compared with countries with no such bans, had $31 \%$ less fighting in males and $42 \%$ less fighting in females.

\section{DISCUSSION}

This study examined the association between bans on corporal punishment and the prevalence of youth violence in a large and diverse sample of countries. It was not an experimental evaluation of policy impact and therefore we are cautious not to infer a causal association with adolescent fighting. Rather, these results reveal a cross-sectional association between national bans of corporal punishment in all settings and less frequent physical fighting in male and female adolescents. This associations did not diminish after differences in country wealth and other factors were statistically controlled, including violent crime (homicides) and social programmes that support parent education and aim to reduce adolescents' exposure to violence at home and at school.

The results also indicate that countries that ban corporal punishment in schools but not in the home (including Canada, the USA and the UK) also have a lower prevalence of fighting than countries with no bans, but only in females. Partial bans on corporal punishment did not relate to the prevalence of fighting in adolescent males. The reason for this gender difference is unclear. It could be that males, compared with females, experience more physical violence outside school settings or are affected differently by corporal punishment by teachers. Further investigation is needed to understand the nature of this gender difference. Overall, the results suggest a graded association between the breadth of corporal punishment bans and the prevalence of frequent physical fighting in children aged 13 years, with more comprehensive bans related to less fighting (figure 2).

Limitations of the study should be noted. First, there was heterogeneity in time when the bans were enacted and enforced and when the youth surveys were carried out. In many countries, laws that restrict or ban the use of corporal punishment were tabled, amended and/or passed around the time that fighting was last measured. To investigate temporality in this association would require baseline data on fighting before prohibition and follow-up data afterwards. A second limitation was the lack of information on the use of corporal punishment by parents, educators and other adults and on adolescents' exposures to such treatment. Further research on the experience of corporal punishment is worthy of further investigation as it may help explain the gender difference found in the association with partial bans. We hypothesised that these constructs might explain an association between corporal punishment bans and youth fighting but, unfortunately, could not test these pathways directly. It remains for further investigation whether national bans on corporal punishment lead to positive changes in child discipline practices or are a simply characteristic of less violent societies. Third, because of the ecological design of the study, the ecological fallacy is a possibility and direction of causality cannot be inferred.

The strengths of the study include the large and diverse sample of countries and independent ratings of fighting by adolescents. To our knowledge, it is one of the largest cross-national analyses of youth violence that has been carried out. Prevalence estimates of frequent fighting used multilevel regressions to account for the clustering effect of fighting within schools and multiple regression was used to control important country-level confounders in tests of the association between bans on corporal punishment and youth violence. 
Beyond the association between corporal punishment, few other country characteristics emerged as predictors of youth fighting. We expected to find less fighting in more affluent countries, ${ }^{33}$ but instead found the lowest prevalence of fighting in males in Cambodia, Myanmar and Malawi and a mix of low-income and high-income countries at both ends of the spectrum (figure 1). The lowest prevalence of fighting in females was found in Costa Rica, Tajikistan and China, where $<1 \%$ of females engage in frequent fighting. Clearly, economic wealth alone does not differentiate societies where youths rarely engage in physical fighting. As well, no significant associations were found with home visitation programmes for child maltreatment or parent education programmes. This result might have been due to the small number of countries that had neither corporal punishment bans nor a home visitation programme $(\mathrm{n}=2)$, and neither corporal punishment bans nor a parent education programme $(\mathrm{n}=4)$, making it difficult to test the association with any precision. Homicides and weapons bans in schools also did not relate to the prevalence of fighting. We used these variables to control for the possibility that youth live in societies with varying propensities for violence, but they did not predict international differences in youth fighting. However, a large gender difference in fighting was apparent. Frequent fighting is more ubiquitous and perhaps culturally normative in male versus female adolescents, while aggression in females is often expressed in non-physical forms.

These findings add to a growing body of evidence on links between corporal punishment and adolescent health and safety. A public health response to the evidence involves regulatory reform and educational campaigns. ${ }^{18} 36$ A growing number of countries have banned corporal punishment as an acceptable means of child discipline and this is an important step that should be encouraged, especially in countries that have seen an effective lobby against such prohibitive approaches. ${ }^{37}$ Where there is insufficient public support for a full ban, Zolotor and Puzia recommended partial bans as an interim solution while also supporting positive and non-violent approaches to child discipline. ${ }^{20} 263839$ However, partial bans can also send conflicting messages to parents and put health providers in a non-sensical position of having to educate parents about ways to hit their children safely. Furthermore, this study found no difference in fighting in males between countries with a partial ban and no ban.

Health providers are well positioned to offer practical and effective tools that support such approaches to child discipline. Cultural shifts from punitive to positive discipline happen slowly. ${ }^{19}{ }^{40}$ In the past, there were scant data about the detrimental consequences of adults physically punishing children. This has changed as more evidence supports regulatory and educational public health approaches to protecting children and reducing violence. Moreover, public health messaging must be clear that repealing laws that permit corporal punishment is not synonymous with an absence of child discipline. All children have the right to that does not endanger their well-being and respects their right to exist.

Acknowledgements The authors would like to thank Natalya Maksymec (Canada), Priscilla Reddy, Ronel Sewpaul (South Africa), Pat Bullen, Terryann Clark, (New Zealand) and all the investigators of the HBSC and GSHS studies. The HBSC is a WHO/EURO collaborative study; International Coordinator of the HBSC study is Jo Inchley, University of St Andrews, Scotland; Data Bank Manager is Oddrun Samdal, University of Bergen, Norway. The HBSC countries included in this analysis (current responsible principal investigator) were Armenia (S Sargsyan), Austria (R Felder-

Puig), Belgium (D Piette, C Vereecken), Canada (W Pickett, W Craig), Croatia (M Kuzman), Czech Republic (M Kalman), Denmark (M Rasmussen) Estonia (K Aasvee), Finland (J Tynjälä), France (E Godeau), Germany (P Kolip), Greece (A Kokkevi), Greenland (B Niclasen), Hungary (Á Németh), Iceland (Á Arnarsson), Ireland (S Nic Gabhainn), Israel (Y Harel-Fisch), Italy (F Cavallo), Latvia (I Pudule), Lithuania (A Zaborskis), Luxembourg (Y Wagner), Macedonia (L Kostarova Unkovska), The Netherlands (W Vollebergh), Norway (0 Samdal), Poland (J Mazur), Portugal (MGDM), Russia (0 Churganov), Slovakia (A Madarasova Geckova), Slovenia Croatia (M Kuzman), Czech Republic (M Kalman), Denmark (M Rasmussen) (H Jericek), Spain (C Moreno), Sweden (L Augustine), Switzerland (E Kuntsche), Turkey (0 Ercan), Ukraine (0 Balakireva), UK (F Brooks; C Roberts) and USA (R lannotti). The GSHS was coordinated and supported by WHO and CDC in collaboration with Unicef, Unesco and UNAIDS. The authors would like to thank all the school principals and students involved in these surveys for the use of their data.

Contributors FJE, PDD and WP conceptualised and designed the study, wrote up the results and revised the manuscript. FJE, GG and KER cleaned and analysed the data and wrote sections of the manuscript. VM and SW reviewed the literature, interpreted the findings and wrote sections of the manuscript.

Funding This work was supported by grants from the Canadian Institutes for Health Research (CIHR; grant numbers MOP133519, MOP341188), Social Sciences and Humanities Research Council (grant number 435-2014-2160) and Canada Research Chairs programme.

Competing interests None declared.

Patient consent Not required.

Ethics approval This survey was approved by the Institutional Review Board of the Faculty of Medicine, McGill University.

Provenance and peer review Not commissioned; externally peer reviewed.

Data sharing statement Original microdata files can be requested from the HBSC Data Management Centre (http://www.uib.no/en/hbscdata) and Centers for Disease Control and Prevention (www.cdc.gov/gshs).

Open access This is an open access article distributed in accordance with the Creative Commons Attribution Non Commercial (CC BY-NC 4.0) license, which permits others to distribute, remix, adapt, build upon this work non-commercially, and license their derivative works on different terms, provided the original work is properly cited, appropriate credit is given, any changes made indicated, and the use is non-commercial. See: http://creativecommons.org/licenses/by-nc/4.0/.

\section{REFERENCES}

1. Grogan-Kaylor A. The effect of corporal punishment on antisocial behavior in children. Soc Work Res 2004;28:153-62.

2. Straus MA. Prevalence, societal causes, and trends in corporal punishment by parents in world perspective. Law and Contemporary Problems 2010;73:1-30.

3. UNICEF. Hidden in Plain Sight: a statistical analysis of violence against children. New York: UNICEF, 2015.

4. Bussmann K-D. Evaluating the subtle impact of a ban on corporal punishment of children in Germany. Child Abuse Review 2004;13:292-311.

5. Piché G, Huỳnh C, Clément Marie-Ėve, et al. Predicting externalizing and prosocial behaviors in children from parental use of corporal punishment. Infant Child Dev 2017;26:e2006.

6. Aucoin KJ, Frick PJ, Bodin SD. Corporal punishment and child adjustment. J Appl Dev Psychol 2006;27:527-41.

7. Lansford JE, Chang L, Dodge KA, et al. Physical discipline and children's adjustment: cultural normativeness as a moderator. Child Dev 2005;76:1234-46.

8. Ohene SA, Ireland M, McNeely C, et al. Parental expectations, physical punishment, and violence among adolescents who score 
positive on a psychosocial screening test in primary care. Pediatrics 2006;117:441-7.

9. Pagani LS, Tremblay RE, Nagin D, et al. Risk factor models for adolescent verbal and physical aggression toward mothers. Int $\mathrm{J}$ Behav Dev 2004;28:528-37.

10. You S, Lim SA. Development pathways from abusive parenting to delinquency: the mediating role of depression and aggression. Child Abuse Negl 2015;46:152-62.

11. Afifi TO, Brownridge DA, Cox BJ, et al. Physical punishment, childhood abuse and psychiatric disorders. Child Abuse Negl 2006;30:1093-103.

12. Turner HA, Muller PA. Long-term effects of child corporal punishment on depressive symptoms in young adults potential moderators and mediators. J Fam Issues 2004;25:761-82.

13. Javo C, Rønning JA, Heyerdahl S, et al. Parenting correlates of child behavior problems in a multiethnic community sample of preschool children in northern Norway. Eur Child Adolesc Psychiatry 2004;13:8-18.

14. Rodriguez CM. Parental discipline and abuse potential affects on child depression, anxiety, and attributions. J Marriage Fam 2003;65:809-17.

15. Gershoff ET, Grogan-Kaylor A. Spanking and child outcomes: Old controversies and new meta-analyses. J Fam Psychol 2016;30:453-69.

16. Straus MA, Paschall MJ. Corporal punishment by mothers and development of children's cognitive ability: a longitudinal study of two nationally representative age cohorts. J Aggress Maltreat Trauma 2009;18:459-83.

17. MacKenzie MJ, Nicklas E, Waldfogel J, et al. Corporal punishment and child behavioral and cognitive outcomes through 5 years-of-age: Evidence from a contemporary urban birth cohort study. Infant Child Dev 2012;21:3-33.

18. Durrant JE, Ensom R. Twenty-Five Years of Physical Punishment Research: What Have We Learned?*. J Korean Acad Child Adolesc Psychiatry 2017;28:20-4.

19. Fulu E, Miedema S, Roselli T, et al. Pathways between childhood trauma, intimate partner violence, and harsh parenting: findings from the UN multi-country study on men and violence in Asia and the Pacific. Lancet Glob Health 2017;5:e512-22.

20. Bandura A. Social learning theory of aggression. J Commun 1978;28:12-29.

21. Tedeschi JT, Felson RB. Violence, aggression, and coercive actions. Washington, DC: American Psychological Association, 1994.

22. Huesmann LR. Aggressive behavior: current perspectives. New York: Plenum Press, 1994.

23. Anderson CA, Bushman BJ. Human aggression. Annu Rev Psychol 2002;53:27-51.

24. The United Nations. Convention on the rights of the child. Treaty Series 1989;1577:3.
25. Yoon JS, Barton E, Taiariol J. Relational aggression in middle school: educational implications of developmental research. J Early Adolesc 2004;24:303-18.

26. Zolotor AJ, Puzia ME. Bans against corporal punishment: a systematic review of the laws, changes in attitudes and behaviours. Child Abuse Review 2010;19:229-47.

27. Inchley J, Currie C, Young T, et al. Growing up unequal: gender and socioeconomic differences in young people's health and well-being: Health Behaviour in School-aged Children (HBSC) study: international report from the 2013/14 Survey. Health Policy for Children and Adolescents (no. 7). Copenhagen: World Health Organisation, 2016.

28. Clark T, Fleming T, Bullen P, et al. Health and well-being of secondary school students in New Zealand: trends between 2001, 2007 and 2012. J Paediatr Child Health 2013;49:925-34.

29. Reddy SP, James S, Sewpaul R, et al. Umthente Uhlaba Usamila: the 3rd South African National youth risk behaviour survey 2011. Pretoria, South Africa: Human Sciences Research Council, 2013.

30. Global Initiative to End All Corporal Punishment of Children. Global progress towards prohibiting all corporal punishment. http://www. endcorporalpunishment.org/assets/pdfs/legality-tables/Globalprogress-table-with-terrs-alphabetical.pdf (retrieved on 12 Oct 2017).

31. World Health Organization. Global status report on violence prevention. Geneva: World Health Organization, 2014.

32. World Bank. Gross national income per capita, Atlas method (current US\$). World Bank Database. 2016 http://data.worldbank.org/ indicator/NY.GNP.ATLS.CD

33. Elgar FJ, McKinnon B, Walsh SD, et al. Structural determinants of youth bullying and fighting in 79 countries. J Adolesc Health 2015;57:643-50.

34. Sterne J. Meta-analysis in Stata: an updated collection from the Stata Journal. 1st edn. College Station, Texas: Stata Press, 2009

35. Burnham KP, Anderson DR. Model selection and multimodel inference: a practical information-theoretic approach. 2nd ed. New York: Springer, 2002.

36. Bussman KD, Erthal C, Schroth A. Effects of banning corporal punishment in Europe: a five-nation comparison (pp. 299-322). In: Durrant JE, Smith AB, eds. Global pathways to abolishing physical punishment: realizing children's rights. New York: Routledge, 2011.

37. Mrozek A, Buhrmann A. Parental discipline: a case for keeping Section 43from. http://www.cardus.ca/assets/data/files/2017-01Cardus-Family_-_Parental_Discipline.pdf (retrieved on 25 Mar 2017).

38. Durrant JE, Plateau DP, Ateah C, et al. Preventing punitive violence: preliminary data on the Positive Discipline in Everyday Parenting (PDEP) Program. Can J Commun Ment Health 2014;33:109-25.

39. Keyes K, Leray E, Pez O, et al. Parental use of corporal punishment in Europe: intersection between public health and policy. PloS ONE 2015;10:e0118059

40. Straus MA, Douglas EM, Medeiros RA. The primordial violence: spanking children, psychological development, violence, and crime. New York: Routledge, 2014. 